\title{
RAMIRO DE MAEZTU, CARLOS FUENTES: DOS MOMENTOS DE LA CULTURA HISPÁNICA ANTE EL QUIJOTE
}

\begin{abstract}
«Abrí los ojos para leer lo único que se salvó de nuestro tiempo terrible. [...] Los abrí para leer tres libros: el de la trotaconventos, el del caballero de la triste figura y el del burlador Don Juan. Créeme, Felipe: sólo allí, en los tres libros, encontré de verdad el destino de nuestra historia».
\end{abstract}

C. FUENTES, 1991: 880

Estas enigmáticas y a la vez rotundas palabras son pronunciadas por Ludovico, personaje del escritor mexicano Carlos Fuentes en su novela Terra Nostra al rey Felipe II. Resulta evidente a qué libros se está refiriendo: La Celestina, el Quijote y Don Juan, los mismos libros que componen el título de un ensayo de 1926 del escritor noventayochista Ramiro de Maeztu ${ }^{1}$.

Si nos fijamos en el apartado dedicado a Don Quijote, titulado "Don Quijote o el amor», podemos hallar grandes similitudes con el análisis elaborado por Carlos Fuentes publicado por primera vez en 1976 con el título de Cervantes o la crítica de la lectura, escrito como apéndice a su novela Terra Nostra.

Desde luego, hemos de tener en cuenta que ambos escritores teorizan partiendo de mundos distintos. Maeztu inserto en la España de finales del siglo XIX, principios del XX, y Fuentes en el México de la segunda mitad de nuestro siglo. Sin embargo, son grandes sus afinidades en cuanto que ambos escriben con un sentimiento de preocupación: uno, por el pueblo español que ha sufrido la pérdida de sus últimas colonias; y el otro, por la identidad cultural mexicana y sus relaciones con lo hispánico. Por esto probablemente (pero también por su sentido de la justicia y el amor) es por lo que ambos se sienten tan cercanos a Don Quijote, personaje que proporciona la clave no sólo de su propio mundo sino del mundo moderno, cambiante, evolutivo.

Tanto Fuentes como Maeztu analizan la cultura hispánica a través de estos tres personajes míticos. De hecho, existe una corriente

1 Esto es Don Quijote, Don Juan y la Celestina. 
de pensamiento, que comparten intelectuales como Miguel de Unamuno o Alejo Carpentier, que afirma que el arte es reflejo del alma de un pueblo. Esta búsqueda de los orígenes de la cultura a través de sus mitos fue iniciada por Platón, continuada por Vico y recogida por los pensadores de la generación del 98 y afines, como Américo Castro ${ }^{2}$. Sin duda todos ellos constituyen una parte del bagaje cultural de Carlos Fuentes de manera explícitamente reconocida por él en la bibliografía al ensayo que estoy analizando.

Pero, como ya sabemos, la interpretación mítica de las figuras del arte aplicada al Quijote fue iniciada por los románticos alemanes y, según afirma Anthony Close (1998), continuada por Ortega que favorece su supervivencia en el siglo XX con las teorías expuestas por él en sus Meditaciones del Quijote. Ortega es también uno de los filósofos que Fuentes reconoce como sustrato de sus teorías, aunque esto no es de extrañar si observamos que muchos intelectuales españoles exiliados en México eran discípulos del gran filósofo. Este país tiene en Octavio Paz y en el propio Carlos Fuentes dos de los máximos exponentes del pensamiento acerca de la identidad del ser mexicano y sus relaciones con España. De hecho, ambos son conscientes de que han de volver la vista a los orígenes para conocer su presente, aunque sus planteamientos sean en ocasiones opuestos. Paz entiende que el alma mexicana se halla escindida a causa de la Conquista española. Fuentes, sin embargo, pretende la reconciliación del mexicano consigo mismo, lo que se resuelve finalmente en el reconocimiento del pasado hispánico, doble de luz y sombra que el mexicano hereda y al que ha integrado en su propio ser mirando al futuro con nuevos ojos ${ }^{3}$.

Pero aunque estos presupuestos noventayochistas están en la retaguardia de las tesis de Fuentes no pretendo afirmar que este escritor mexicano es el continuador de su pensamiento con respecto a la gran obra de Cervantes. Es conocida su admiración por dicha generación española ${ }^{4}$ y de hecho existen planteamientos de ésta que Fuentes parece asumir, como la actitud en el estudio de los clásicos. Según señala Anthony Close, los noventayochistas pretenden «[...] una aproximación íntima y viva a los clásicos, que los haga asequibles al lector moderno [...]" (1998: CXLIV) y vemos que tanto Maeztu como Fuentes en su acercamiento a las figuras de Don Quijote, Don Juan y la Celestina destacan aquello que puede ayudar al crecimiento de su pueblo.

\footnotetext{
2 Vid. GONZÁLEZ ECHEVARRÍA (1981: 291).

3 Vid. FUENTES (1994: 9-10).

4 Fuentes la califica de: "[...] espléndida irrupción cultural brutalmente interrumpida por la dictadura fascista» (1994: 88).
} 
De ellos dice Maeztu en el prólogo a su citado ensayo: «Son para nosotros realidades más profundas que las de muchos seres de carne y hueso» (1972: 11). Fuentes también participa de este sentimiento de realidad que le provoca la figura del Quijote ya mitificada por el paso de los siglos. Se pregunta: "¿No es más real Don Quijote que la mayor parte de los seres de carne y hueso?»(1993: 32).

Ambos reflexionan también acerca de la imaginación literaria. Dice Maeztu: «Se podrá alegar que la calidad de los hijos de la fantasía no depende de la literatura que los viste, sino de la imaginación que los engendra» (1972: 12). Esto es, la importancia mítica de estos personajes depende de la grandiosidad de los seres humanos que los crearon, de los que éstos son capaces de imaginar. Asimismo, dice Fuentes: «El escritor y el artista no saben: imaginan. La imaginación es el nombre del conocimiento en literatura y en arte. Quien sólo acumula datos veristas, jamás podrá mostrarnos, como Cervantes o como Kafka, la realidad no visible y sin embargo tan real como el árbol, la máquina o el cuerpo» (1993: 22). La imaginación es mucho más rica que la realidad y a través de ella podemos conocer más allá de lo perceptible por los sentidos. Incluso se pregunta más adelante: «¿Hay realidad que no haya sido, primero, imaginada y deseada?»(1993: 32). Ahí reside la valía del gran escritor: ser capaz de mostrar los mundos invisibles que pueblan su universo imaginativo. Y... ¿quién mejor que Cervantes para ello?

Pero es en concreto el Quijote el que suscita múltiples tesis en todos los escritores de la generación del 98 como ya sabemos, y por supuesto, en Maeztu, ideas que podemos ver reflejadas también en el ensayo de Fuentes sobre el citado libro. Habrá que hacer antes una salvedad: parto de la concepción de ambos escritores como lectores del Quijote que elabora su teoría sobre el mismo, siendo consciente de la diferencia de presupuestos en los que se basan para ello y de la distinción cultural y temporal que entre ellos existe. Si Carlos Fuentes parte de la teoría y crítica literarias del siglo $\mathrm{XX}$, como Kosic, Foucault, Eco, Paz..., Ramiro de Maeztu lo hace desde una visión del Quijote como reflejo del alma española que remite, en última instancia, a la idea ya expuesta anteriormente de la concepción del arte como expresión del espíritu de un pueblo. El Quijote como mito e ideal del español, tanto del siglo XVII como del XIX-XX, pertenece también a la «interpretación simbólica y filosófica de la obra cervantina» (Montero Reguera, 1997b: 29) inaugurada por el alemán Heinrich Heine en 1837 con el que nace «la lectura trascendente del Quijote» (Montero Reguera, 1997b: 29), al calificar a Cervantes como "[...] fundador de la novela moderna» (VV. AA., 1986: 48). El romanticismo revive el pasado, los mitos, 
ensalza los orígenes. Señala A. Close que «A partir de este momento, la crítica decimonónica del Quijote estará marcada por un carácter histórico-nacionalista [...]» (1998: CLIV), carácter que se aprecia en la aproximación crítica que la generación del 98 hace del Quijote, y en concreto Maeztu, en su percepción de esta obra como reflejo de la idiosincrasia del pueblo español de su tiempo, pero aplicable a todos los tiempos.

Una vez hecha esta aclaración me parece interesante resaltar que para ambos el Quijote es obra total, de un pueblo concreto inmerso en una historia determinada, no es una escritura casual sino intencionada y claramente trascendente para la cultura hispánica. Es para Maeztu ejemplo moral a seguir en una época de apatía ${ }^{5}$ como fue el 98 y sus años anteriores y posteriores; y para Carlos Fuentes, novela instauradora de la imaginación moderna, de la creación dentro de la creación que tanto ha influido en la narrativa hispanoamericana.

En un primer momento Maeztu califica al Quijote como «el libro ejemplar de nuestra decadencia» (1972: 20) entendiendo que «la decadencia se marca cuando nos reconocemos vencidos ante el ideal inasequible, cuando se muestran nuestros medios inadecuados para nuestros fines y la realidad se encoge y anonada ante el ideal enhiesto e inalcanzable» (1972: 21). La realidad resulta, por lo tanto, insuficiente para realizar aquello que se desea. Algo similar opina Fuentes del Quijote «es la primera novela de la desilusión; es la aventura de un loco maravilloso que recobra una triste razón" (1994: 83) y la recobra cuando no puede imponer su percepción del mundo porque se cuestiona su existencia desde el exterior: los lectores de la I parte de 1605. Entonces conoce que su mundo es ficticio, descubre la realidad, lo que le produce tristeza y le lleva a la muerte. "La realidad le roba su imaginación» (1994: 81), dice Fuentes, y sin ella don Quijote no tiene razón de ser.

Pero Maeztu dice más. Cuando habla de «nuestra» decadencia, se refiere a la decadencia de España. Su estudio del Quijote pasa por la inserción de esta novela en su contexto histórico social y éste es una España derrotada, cansada, fatigada, ante el fracaso del avance español en la expansión del cristianismo y de la participación en la política europea. Para Fuentes este contexto es indispensable para conocer y entender el Quijote. En su ensayo expone largamente la situación histórica de ortodoxia medieval elevada hasta el extremo en la España contrarreformista. Cita tres fechas para él claves en este sentido y que configuran la época que habitó Cervantes y que engendró al Quijote: 1492, 1521, 1598. La primera

5 Vid. JuAN LÓPEZ MORILlas (1980: 13). 
es la fecha del Descubrimiento de América y de la publicación de la Gramática de Antonio de Nebrija, pero también de la expulsión de los moriscos, imponiendo la "pureza de sangre» en aras de la unidad del reino. La segunda, 1521, es la fecha de la derrota de los comuneros en Villalar, rebelión popular contra los abusos del poder. Y la tercera, 1598, es el año de la muerte del monarca Felipe II que deja a España sumida en una profunda crisis económica. Estas tres fechas tienen para Fuentes un significado común: la explicitación de la intolerancia y de la destrucción de «las tendencias pluralistas y democráticas de la España medieval en tránsito hacia la modernidad» (1994: 55).

Pero Maeztu y Fuentes otorgan al Quijote una función diferente en este contexto. Maeztu cree que es la novela del reposo para el pueblo cansado. Señala: «En los individuos la decadencia es anuncio de muerte. En los pueblos no necesita serlo, sino de una situación nueva, de un período de reposo, de una pérdida de la iniciativa histórica, en la que, a cambio de padecer por algún tiempo el rango, se vuelve a crear otro ideal y la energía con que mantenerlo» (1972: 22). Mientras, Fuentes opina que es la respuesta heterodoxa a la ortodoxia imperante. Cree en el poder de la literatura para ir contracorriente ${ }^{6}$. A través del lenguaje, único medio que posee, Cervantes rompe la escritura y lectura unívocas. En palabras de Carlos Fuentes: «[...] Cervantes fue capaz de ir más allá de la consagración del puro pasado y de la consagración del puro presente a fin de plantearse el problema de la fusión de pasado y presente. La naturaleza ambigua de esta fusión convierte a la novela en un proyecto crítico» (1994: 31-32).

Si para Maeztu Cervantes quiere dar descanso al alma del pueblo español agotado por tanta derrota; para Fuentes su intención es crear una obra que rompa con los moldes de su época e instaure una nueva forma de ver el mundo. Sus opiniones acerca de la intención del autor son bien diferentes, no en vano viven etapas distintas de la historia del pensamiento y la cultura hispánica.

Sin embargo, resultan muy cercanos al afirmar que Cervantes era un hombre reflexivo y plenamente consciente de su tiempo, a la vez que fue un hombre fracasado en sus intenciones vitales. Según Maeztu, desea ser héroe militar y fracasa; se siente poeta pero no llega a alcanzar como tal la altura a la que lo eleva la prosa; e intenta también hacer carrera administrativa sin éxito. Sin duda para Maeztu Cervantes es un idealista que expresa en el Quijote sus anhelos, todo aquello que «hubiera deseado decir al mundo, si se

6 Vid. JACQues Joset (1995: 84). 
hubiera atrevido, o si se le hubiese deparado la ocasión de hablarle» (1972: 33).

Para Fuentes también Cervantes era un hombre derrotado y perfectamente consciente de las realidades de su tiempo «[...] el viejo, pobre y triste autor de una novela concebida detrás de los barrotes y con cuyas magras regalías apenas pudo pagar deudas acumuladas [...]» (1994: 14). Pero es por encima de todo "el fundador de la novela europea moderna» (1994: 15). Fuentes destaca siempre la valía literaria del Quijote y de Cervantes, lo que supusieron para la literatura posterior de habla hispana, mientras que Maeztu se mantiene en un nivel de búsqueda de un ideal español.

Así compara a Hamlet y Don Quijote como dos formas distintas de realización de un mismo modelo de sacrificio y generosidad: el primero insta al lector a la acción mientras que el segundo provoca el reposo. Estas reacciones se suscitan en el espectador como contraposición al análisis inactivo de Hamlet y a la acción siempre fracasada de Don Quijote. Y considera que son los máximos representantes del alma de sus pueblos: «El Hamlet es la tragedia de Inglaterra; el Quijote es el libro clásico de España. En torno a las dos obras se ha venido cristalizando el alma de los dos pueblos. Inglaterra ha conquistado un imperio; España ha perdido el suyo» (1972: 32).

A su vez, Fuentes también compara ambos personajes bajo parámetros afines. Para él Hamlet es la realización de la ideología erasmista en tanto que es duda, crítica. Sin embargo, Don Quijote es "un caballero de la fe» (1994: 75), para él no existe la duda de su mundo, simplemente cree en la justicia y el amor. Por lo tanto, Hamlet insta al «todo es posible», al cuestionamiento de los hechos y las realidades y Don Quijote a todo lo contrario, aunque finalmente veamos cómo tiene que cambiar su concepción del mundo, lo que le lleva a la muerte.

El estudio comparativo de ambos personajes, Hamlet y Don Quijote, que realizan Maeztu y Fuentes ya había sido desarrollado en el siglo XIX, especialmente a cargo de la crítica rusa cuyos iniciadores fueron Pushkin y Gogol y sus seguidores más destacados Fedor Dostoyevski e Iván Turgueniev ${ }^{7}$. Maeztu ensalza las teorías de éste último cuando declara en su ensayo que "Pocas páginas se habrán dedicado al libro español tan comprensivas y amorosas [...]» (1972: 27). Turgueniev es el autor de un artículo titulado precisamente "Hamlet y Don Quijote» del año 1860 en el que habla de ambos personajes en términos similares a los de nuestros críticos en comparación. Don Quijote es representación de la fe, el entu-

7 Vid. Montero Reguera (1997b: 43). 
siasmo, el idealismo, la humildad, la paciencia, la moral..., la acción. Dice de él que es «La fe ante todo, la fe en algo eterno, inconmovible, en la verdad; en una palabra, en la verdad que se encuentra fuera del individuo, que no se le entrega fácilmente, que reclama dedicación y sacrificios, pero que se alcanza por la perseverancia y la fuerza del sacrificio. Don Quijote está enteramente impregnado de la fidelidad a su ideal, por el cual está dispuesto a soportar toda clase de privaciones y sacrificar su vida, que tan sólo valora como medio para la encarnación del ideal, la restauración de la verdad y de la justicia en la tierra. [...] No hay en él el menor vestigio de egoísmo [...] él cree, cree firmemente y sin mirar atrás. Por eso no tiene miedo, es paciente y se contenta con la comida más frugal, los vestidos más pobres [...]. Humilde de corazón, es grande y temerario de espíritu; su religiosidad enternecedora no restringe su libertad; aunque sin vanidad, jamás desconfía de sí mismo, ni de su vocación, ni aún de su fuerza física; su voluntad es una voluntad indomable» (1986: 72-74). Mientras que Hamlet es análisis, egoísmo, falta de fe, escepticismo, duda, inmovilidad, pensamiento.

Otros críticos contemporáneos de Maeztu, como Unamuno, también ostenta la misma opinión acerca de Don Quijote. Según A. Close, para don Miguel es «un héroe mítico, vate de la fe propia de nuestro tiempo" (1998: CXLIII).

Pero también para Fuentes Don Quijote es un «héroe español» en la medida en que «el proyecto trascendente no puede ser herido por los accidentes de la banalidad cotidiana» (1994: 90). ¿No es esto lo mismo que decía Maeztu cuando hablaba del contenido del Quijote?: "No se trata únicamente, como vemos, de los libros de caballería, sino del ideal caballeresco, del impulso que empuja a los espíritus nobles a intentar la realización de empresas grandes, sin reparar en los peligros ni detenerse a calcular las propias fuerzas» (1972: 23). Esto lo expresa de otro modo Ortega al exponer su teoría acerca de la voluntad autocreadora que poseen todos los seres humanos y que les obliga a obviar lo cotidiano para alcanzar sus ideales ${ }^{8}$

Por otro lado, Maeztu habla de la identificación de Cervantes con Don Quijote como un idealista, un viejo fracasado que anhela algo que no alcanza y que escribe el Quijote para exorcizar sus demonios, sus desengaños. Al presentar los ideales juveniles bajo la apariencia de un anciano provoca la locura del personaje, a la vez que suscita la risa en el espectador que se relaja con lo que se consigue la intención de descanso buscada por Cervantes, según argumenta

8 Vid. A. Close (1998: CXLVI). 
Ramiro de Maeztu. Fuentes, como ya sabemos, otorga a Cervantes un papel más trascendente en la escritura de su novela.

Vuelven a unirse en el concepto del amor y de la justicia por el que lucha don Quijote. Para Maeztu «Don Quijote es el prototipo del amor, en su expresión más elevada del amor cósmico [...]» (1972: 69), el amor que todo lo puede, un amor lleno de fuerza que se basará en una visión clara de la realidad. Y Fuentes destaca a Don Quijote como el que ama y cree a pesar de todo. "El concepto quijotesco de la justicia es un concepto del amor. Y a través del amor, la justicia abstracta de Don Quijote adquiere una plenitud concreta» (1994: 92). Y además: «(...) el amor del cual nos habla Don Quijote es un acto democrático, que sobrepasa las distinciones de clase y encarna en la más humilde muchacha campesina» (1994: 94). Por lo tanto, la justicia a través del amor se vuelve también democrática, una justicia para todos puesto que Cervantes no abogaba por una minoría opresora pero tampoco por una mayoría gregaria.

En ambos el amor y la justicia son el motor de nuestro héroe, aunque Fuentes lo vea desde una perspectiva política democrática. Esto se entiende, una vez más, por el hecho de que los dos analizan una misma obra desde momentos diferentes de la historia y la cultura.

Ramiro de Maeztu lo rescata como «el libro de nuestra filosofía nacional» (1972: 58) en el cual encuentra un modelo para el español que está viviendo (o ha vivido) la pérdida de los restos del imperio. Es la novela de la decadencia, como decía al principio, pero de una decadencia que sirve para el reposo del pueblo con la intención de recobrar fuerzas para acometer futuras empresas nacionales. Y es un ejemplo de los valores patrios que no deben desaparecer y el amor, basado en una visión consciente de la realidad española para poder cambiar el destino de la misma.

Carlos Fuentes lo destaca como novela que funda la modernidad, que enseña una nueva manera de ver el mundo, crítica, abierta, cambiante, que deshecha la rigidez y la lectura única. Un ejemplo de búsqueda de la justicia, de la utopía en la que creían los españoles del tiempo del Descubrimiento de América y de la utopía que supone para Fuentes, escritor mexicano del siglo $\mathrm{xx}$, la realización del pueblo latinoamericano en su propia identidad, con sus propias características culturales. Una novela y unos personajes construidos con palabras, esto es, «la único que es de todos» (1994: 101).

MACARENA CUIÑas GÓMEZ 


\section{BIBLIOGRAFÍA}

BASANTA, ÁNGEL, "Cervantes y el Quijote en algunas novelas españolas de nuestro tiempo", Actas del I-CINDAC, Alcalá de Henares, 29/30 nov. Y 1/2 dic. 1988. Barcelona, Anthropos, 1988, 35-51.

Canavaggio, Jean, Cervantes. En busca del perfil perdido. Madrid, Espasa, 1992.

Close, ANTHONY, "Las interpretaciones del Quijote», en Miguel DE CERvantes SAAVEdRA, Don Quijote de la Mancha. Barcelona, Crítica, 1998, CXLII-CLXV.

FERNÁNDEZ FERRER, ANTONIO, "La "abismación" cervantina en la literatura hispanoamericana", Actas del II-CIAC, Alcalá de Henares, 6/9 nov. 1989. Barcelona, Anthropos, 1989, 327-336.

FERnÁNDEZ Muñoz, MARÍA TERESA, «El lenguaje profanado (Terra Nostra, de Carlos Fuentes)», Cuadernos hispanoamericanos, 359, mayo 1980, 419-428.

Fuentes, CARlos, Terra Nostra. Madrid, Espasa-Calpe, Colección Austral, 1991.

-, "Quinientos años después (1492-1992)», conferencia pronunciada en el Centre Cultural Bancaixa. Peñafort: Bancaixa, Caixa d'Estalvis de València, Castelló i Alacant, 26-XI-1991.

-, Geografía de la novela. Madrid, Alfaguara, 1993.

-, Cervantes o la crítica de la lectura. Alcalá de Henares, Centro de Estudios Cervantinos, 1994.

GonZÁlez-EcheVerRía, RoBerto, «Terra Nostra: Teoría y Práctica». Pittsburgh (PA), Revista iberoamericana, XLVII, 116-117, 1981, 289-299.

Herrero, JaVIER, "Carlos Fuentes y las lecturas modernas del Quijote». Pittsburgh (PA), Revista iberoamericana, XLV, 108-109, 1979, 555-562.

INMAN FOX, E., «Las ideas literarias del joven Maeztu», Francisco Rico, ed., Historia y crítica de la literatura española. Modernismo y 98, vol. VI, al cuidado de José-Carlos Mainer. Barcelona, Crítica, 1980, 31-36.

JOSET, JACQUES, "Carlos Fuentes o la lectura especular de Cervantes», Historias cruzadas de novelas hispanoamericanas. Madrid, Iberoamericana, 1995, 79-89.

LÓPEZ MORILlaS, JUAN, "Las consecuencias de un desastre», Francisco Rico, ed., Historia y crítica de la literatura española. Modernismo y 98, vol. VI, al cuidado de José-Carlos Mainer. Barcelona, Crítica, 1980, 11-17.

Maeztu, Ramiro De, Don Quijote, Don Juan y la Celestina. Madrid, Espasa-Calpe, Colección Austral, 1972.

Montero RegUeRA, JosÉ, "La recepción del Quijote en Hispanoamérica (siglos XVII al XIX)», Cuadernos hispanoamericanos, 500, febrero 1992, 133-140.

-, El Quijote y la crítica contemporánea. Alcalá de Henares, Centro de Estudios Cervantinos, 1997a.

- "La crítica sobre Cervantes en el siglo XIX", en Cervantes y el mundo cervantino en la imaginación romántica, Carlos Reyero, ed., 1997b, 29-43.

ORTEGA, JULIO, "Carlos Fuentes: para recuperar la tradición de la Mancha». Pittsburgh (PA), Revista iberoamericana, LV, 1989, 637-654.

Paz, Octavio, El laberinto de la soledad. Madrid, Cátedra, 1993.

Polic Bobic, MirJana, "Sobre los motivos cervantinos en dos novelas de J. J. Fernández de Lizardi», Actas del II-CINDAC, Alcalá de Henares, 6-9 de nov. 1989. Barcelona, Anthropos, 1989, 293-300.

RAMSDEN, HERBERT, «El problema de España», Francisco Rico, ed., Historia y crítica de la literatura española. Modernismo y 98, vol. VI, al cuidado de José-Carlos Mainer. Barcelona, Crítica, 1980, 20-26.

URIBE-ECHEVARRIA, JUAN, Cervantes en las letras hispanoamericanas (Antología y crítica). Chile, Ediciones de la Universidad de Chile, 1949.

VV. AA., Cervantes. Madrid, José Esteban, editor, 1986.

VV. AA., La poética invención de la memoria: el mundo, creación de la palabra. Anthropos, 91 Monográfico sobre Carlos Fuentes (diciembre 1988). 